\title{
AACSB ACCREDITED INSTITUTIONS AND THE WEB 2.0: LAGGING BEHIND BUSINESSES IN SOCIAL NETWORKING IMPLEMENTATION
}

\author{
Carl J. Case, St. Bonaventure University, ccase@sbu.edu \\ Darwin L. King, St. Bonaventure University, dking@sbu.edu
}

\begin{abstract}
Web 2.0 electronic social networking technologies are providing organizations with new platforms for communication. Because previous research has found that businesses are embracing these technologies, this study was undertaken to examine whether institutions of higher learning have seen similar adoption rates. As a result, this paper examines web pages of the AACSB accredited schools of business to determine the implementation and usage of electronic social networking. Results indicate that although $39 \%$ of the AACSB accredited institutions are utilizing electronic social networking, they are lagging behind business implementation in terms of percentage of organizations and number of technologies used per organization. Furthermore, only 34\% of schools utilize two or more networking technologies. The primary products include Facebook, Twitter, YouTube, and LinkedIn. In terms of institutional control, private institutions are more likely to utilize a given technology and use more technologies per school than public institutions.
\end{abstract}

Keywords: AACSB, Electronic Social Networking, Facebook, Twitter, YouTube, LinkedIn, Empirical Study, Blog, Web 2.0

\section{INTRODUCTION}

The Web 2.0 is commonly associated with applications and technologies that allow users to create, edit, and distribute content [13]. This includes web-based communities, social networking sites, video-sharing sites, blogs, wikis, and so on [30]. Web 2.0 skills have even been rated as one of the 11 hottest information technology skills for 2011 [18].

Web 2.0 usage and expenditures have been steadily rising. For example, an InformationWeek 500 survey found that in 2009 82\% of banking and financial service institutions are using wikis, blogs, and other social networking tools for internal collaboration and knowledge sharing [17]. Gartner estimates that annual spending on enterprise social software will increase to $\$ 1.06$ billion in 2012, from the $\$ 280$ million spent in 2007 [11].

Individuals and organizations have both jumped on the social networking bandwagon. The American Association for Retired Persons (AARP), for example, estimates that there are 26.6 million Americans ages 50 and over who network online [2]. A recent AARP survey found that $82 \%$ use Facebook, $16 \%$ use MySpace, $15 \%$ use LinkedIn, $9 \%$ use Twitter, and 9\% use another site. Sixty-two percent of respondents use social networking sites to connect to their children, 36\% have links to grandchildren, and 73\% have linked to other relatives. Half of the respondents first learned about social media from a family member, most often one of their children.

In terms of businesses, a 2009 InformationWeek 500 study found that $42 \%$ of companies used wikis, blogs, or other social networking tools to connect to customers, suppliers, and partners [19]. By 2010, social networking increased to $72 \%$ of these firms. InformationWeek 500's number one company, mutual fund giant Vanguard Group, began using social networking to help individuals who run company $401(\mathrm{k})$ plans interact with one another through moderated online discussions. However, only $27 \%$ of the InformationWeek 500 companies encourage employees to use consumer-oriented apps they find useful.

According to Gartner, by 2014, social networking services will replace electronic mail as the primary vehicle for interpersonal communication by as many as 20 percent of business users [21]. Interestingly, however, the Harrisburg University of Science and Technology blacked out social media for one week in September 2010 [16]. 


\title{
Issues in Information Systems
}

\author{
Volume XII, No. 2, pp. 1-8, 2011
}

The ban was not implemented as a punishment but as a way for individuals to think critically about the prevalence of social media.

\section{THE TECHNOLOGIES}

In practice, electronic social networking takes the form of consumer-oriented products such as Facebook, Twitter, YouTube, and LinkedIn. It is also evidenced in the blogosphere. In addition, businesses utilize a variety of other social networking products. These include internal access-controlled applications such as Socialcast, Socialtext, and Yammer [20,29]. IBM also utilizes a homegrown social networking tool named Beehive [11].

In 2010, Facebook, became the number one most visited site by those in the U.S. It had 8.93\% of all U.S. visits between January and November 2010. Google, which had been in the top spot in 2009, slipped to the number two position with 7.19\% of all visits according to Hitwise, an Internet analytics firm [10]. Yahoo! Mail ranked third with $3.52 \%$ of all visits, while the main Yahoo! site was fourth with $3.3 \%$ of all visits. YouTube was fifth with $2.65 \%$ of all site visits.

Twitter, launched in July 2006 and named by eWeek as one of the top 20 technologies that changed the decade, is the dominant microblogging social network service [8]. In November 2010 alone, complete.com estimated that there were more than 26 million unique and 174 million site visits [6]. A Pew Research study released in December 2010 further revealed that $8 \%$ of American adults who use the Internet also use Twitter [26].

LinkedIn, one of the premier professional social networks, has more than 90 million members in over 200 countries [15]. A new member joins LinkedIn approximately every second and about half of its members are outside the U.S. According to LinkedIn, executives from all Fortune 500 companies are LinkedIn members.

YouTube, founded in 2005, is the world's most popular online video community [28]. Each day, two billion videos are viewed. During every minute, 24 hours of video is uploaded. The user base is broad in age range, 18-55, evenly divided between males and females, and spanning all geographies. Fifty-one percent of users go to YouTube weekly or more often, and 52 percent of 18-34 year-olds share videos often with friends and colleagues.

Another aspect of the Web 2.0 that has been enormously popular is that of blogging. Technorati, a blog search engine, tracks more than 1.25 million blogs [27]. A 2010 survey found that two-thirds of bloggers are male and $65 \%$ are age 18-44. In addition, bloggers are more affluent and educated than the general population with $79 \%$ having college degrees [25].

\section{THE CHALLENGES OF SOCIAL NETWORKING}

The rise of the Web 2.0 can create challenges. The organization, its employees, customers, and business partners may be vulnerable to an attack as user-contributed content is a major source of malware and personal information [22]. Another challenge with regard to social networking is the lack of hard return on investment metrics [7].

Security and privacy can also pose challenges. Security is generally defined as how well a site can thwart attacks while privacy deals with how much data a social networking service collects and how it shares that data [5]. Privacy is challenging because user privacy settings may be confusing and users have the ability to control what information they place on a site. Privacy violations may also occur because of breaches on a social networking site or because of errors at the social networking site. In 2010, for example, a bug in Facebook's messaging service sent electronic mail to the wrong mail boxes [9]. 


\section{Issues in Information Systems}

Volume XII, No. 2, pp. 1-8, 2011

Finally, a Deloitte survey of over 400 companies found that the top three business objectives for social media were to generate more word of mouth (38\% of respondents), increase customer loyalty (34\%), and increase product or brand awareness (30\%). However, the primary obstacles to making online communities work included getting people to engage and participate (30\% of respondents), attracting people to the community (24\%), and getting people to keep coming back (21\%) [24].

\section{PREVIOUS RESEARCH}

Several studies have been conducted to examine the Web 2.0. Previous research has examined factors influencing user adoption of Internet social networks [23], utilization of social network analysis [14], and social network website usage by individualist and collectivist nations [3].

A 2010 study also found that the Fortune 200 firms are embracing these new technologies. Nearly three-quarter, or $71 \%$, of these firms have implemented electronic social networking and $64.5 \%$ of firms have a Twitter account [4]. In addition, 44\% of the Fortune 200 make use of at least two social networking technologies. Although participation varies by industry sector, $79 \%$ of the companies utilizing Twitter use the technology for news distribution. Twitter is used to a much lesser extent for marketing/promotions, customer service, and human resources.

A 2010 InformationWeek "Social Networking In The Enterprise Survey" found similar results. Eight-nine percent of 624 business technology company respondents stated their company uses at least one type of social networking [12]. However, only $10 \%$ considered their internal social networking initiatives a great success. The most used functions of the enterprise social networking was the online directory with Facebook style profiles (22\% report heavy use), wikis (13\%), company discussion boards (7\%), and internal blogs (5\%). The top challenges were user adoption (35\%), explaining the role of social networking (21\%), the support time requirements (16\%), and increasing employee usage (15\%). While 7\% performed detailed tracking and analysis of user activity and participation levels, $63 \%$ were not tracking any activity. In terms of situations that the company has a formal process in place, 32\% have a policy with regard to posting of official company-related announcements and statements on social networking sites, $26 \%$ with regard to inappropriate employee comments online, $21 \%$ relative to customer complaints posted on e-commerce sites, $14 \%$ with regard to customer complaints posted on Facebook or MySpace, and $12 \%$ relative to customer complaints posted via Twitter. However, $43 \%$ had no formal process in place.

Given the recent publicity with regard to social networking, this study was undertaken to better understand the state of social networking at the Association to Advance Collegiate Schools of Business (AACSB) accredited schools of business. Colleges, for example, could use social networks for student recruiting, fund raising, business networking, security alerts, news distribution, curriculum planning, and so on.

This research, therefore, examines several questions. Do the AACSB accredited schools of business utilize electronic social networking and if yes, which technologies are implemented? Is there a relationship between the use of the various social networking technologies? Does institutional control affect implementation? Results are important in helping institutions of higher learning to better understand social network technology implications and to assist in identifying potential usage opportunities.

\section{RESEARCH DESIGN}

This study utilized the AACSB website [1] list of the AACSB accredited schools of business to obtain institution names and identify each school's website URL. Each institution's website was then examined to determine Twitter, Facebook, LinkedIn, YouTube, Flickr, and other web 2.0 technology utilization.

Demographic data such as 


\title{
Issues in Information Systems
}

\author{
Volume XII, No. 2, pp. 1-8, 2011
}

institutional control was obtained through the research office at AACSB International. Social networking utilization was also examined to determine if there were correlations between the use of any two technologies.

\section{RESULTS}

A review of the 600 AACSB accredited schools of business found that institutions utilize a variety of social networking technologies (Table 1). The most commonly used technologies include Facebook (37.8\% of schools), Twitter (30.3\% of schools), YouTube (21.3\% of schools), and LinkedIn (20.2\% of schools). The least utilized technologies include Flickr (9.2\% of schools) and blogs (5.5\% of schools).

Table 1. Overall Social Network Usage

\begin{tabular}{||l|r|r|r|r|r|r|r||}
\hline & Facebook & Twitter & YouTube & LinkedIn & Flickr & Blog & Other \\
\hline \hline Schools That Utilize & $37.8 \%$ & $30.3 \%$ & $21.3 \%$ & $20.2 \%$ & $9.2 \%$ & $5.5 \%$ & $6.5 \%$ \\
\hline $\begin{array}{l}\text { Schools That Do Not } \\
\text { Utilize }\end{array}$ & $62.2 \%$ & $69.7 \%$ & $78.7 \%$ & $79.8 \%$ & $90.8 \%$ & $94.5 \%$ & $93.5 \%$ \\
\hline Total & $100.0 \%$ & $100.0 \%$ & $100.0 \%$ & $100.0 \%$ & $100.0 \%$ & $100.0 \%$ & $100.0 \%$ \\
\hline
\end{tabular}

Table 2 details the "other" (least common) social networking technologies utilized by schools of business. These were implemented by $6.5 \%$ of schools and include Alumni Network, Daily Motion, Delicious, Foursquare, Friendfeed, iTV, iTunes, MySpace, Okurt, Slideshare, Smugsmug, Viadeo, and Vimeo. The most common programs include iTunes (12 schools) and Vimeo (8 schools).

Table 2. Breakdown of Other Social Networking Technologies

\begin{tabular}{||l|r||}
\hline \multicolumn{1}{|c|}{ Program } & $\begin{array}{c}\text { Number } \\
\text { of } \\
\text { Schools }\end{array}$ \\
\hline \hline Alumni Network & 1 \\
\hline Daily Motion & 2 \\
\hline Delicious & 5 \\
\hline Foursquare & 4 \\
\hline Friendfeed & 1 \\
\hline iTV & 1 \\
\hline iTunes & 12 \\
\hline MySpace & 2 \\
\hline Okurt & 2 \\
\hline Slideshare & 2 \\
\hline Smugsmug & 1 \\
\hline Viadeo & 2 \\
\hline Vimeo & 8 \\
\hline \hline
\end{tabular}

Relative to social networking technology utilization, $5 \%$ of schools employ only one technology (Table 3). Six 


\title{
Issues in Information Systems
}

\author{
Volume XII, No. 2, pp. 1-8, 2011
}

percent use two technologies, $11 \%$ use three technologies, $9 \%$ use four technologies, $5 \%$ use five technologies, $2 \%$ use six technologies, and 1\% use seven technologies. Overall, 39\% of the AACSB accredited schools of business use at least one form of electronic social networking.

Table 3. Usage of Multiple Social Networking Technologies

\begin{tabular}{||c|r|r||}
\hline \multicolumn{1}{|c|}{ Type } & Percentage & \multicolumn{1}{|c|}{$\begin{array}{c}\text { Number } \\
\text { of } \\
\text { Schools }\end{array}$} \\
\hline \hline Only 1 Technology & $5 \%$ & 32 \\
\hline Uses 2 Technologies & $6 \%$ & 36 \\
\hline Uses 3 Technologies & $11 \%$ & 66 \\
\hline Uses 4 Technologies & $9 \%$ & 56 \\
\hline Uses 5 Technologies & $5 \%$ & 32 \\
\hline Uses 6 Technologies & $2 \%$ & 13 \\
\hline Uses 7 Technologies & $1 \%$ & 3 \\
\hline Total & $39 \%$ & 238 \\
\hline
\end{tabular}

Social networking utilization was next examined to determine if there were correlations between the use of any two technologies. Table 4 illustrates that there are correlations significant at the .01 level (2-tailed test) for all six technologies. In other words, for example, the use of Facebook was significantly positively correlated with the use of Twitter.

Table 4. Social Networking Pearson Correlations

\begin{tabular}{||l|r|r|r|r|r|r||}
\hline \hline Technology & \multicolumn{1}{|c|}{ Facebook } & \multicolumn{1}{c|}{ Twitter } & YouTube & \multicolumn{1}{c|}{ LinkedIn } & \multicolumn{1}{l|}{ Flickr } & \multicolumn{1}{c|}{ Blog } \\
\hline \hline Facebook & 1 & $.816^{* *}$ & $.642^{* *}$ & $.601^{* *}$ & $.407^{* *}$ & $.279^{* *}$ \\
\hline Twitter & $.816^{* *}$ & 1 & $.674^{* *}$ & $.563^{* *}$ & $.431^{* *}$ & $.254^{* *}$ \\
\hline YouTube & $.642^{* *}$ & $.674^{* *}$ & 1 & $.468^{* *}$ & $.413^{* *}$ & $.249^{* *}$ \\
\hline LinkedIn & $.602^{* *}$ & $.563^{* *}$ & $.468^{* *}$ & 1 & $.315^{* *}$ & $.298^{* *}$ \\
\hline Flickr & $.407^{* *}$ & $.431^{* *}$ & $.413^{* *}$ & $.315^{* *}$ & 1 & $.202^{* *}$ \\
\hline Blog & $.279^{* *}$ & $.254^{* *}$ & $.249^{* *}$ & $.298^{* *}$ & $.202^{* *}$ & 1 \\
\hline
\end{tabular}

** Correlation significant at the .001 level (2-tailed)

Table 5 provides a breakdown of social network usage by institutional control. In terms of the 406 public institutions, 36.7\% use Facebook, 28.1\% use Twitter, 17.7\% use YouTube, 18.7\% use LinkedIn, 7.9\% use Flickr, $5.7 \%$ use a blog, and $5.9 \%$ use another social networking product. In terms of the 194 private institutions, $40.2 \%$ use Facebook, 35.1\% use Twitter, 28.9\% use YouTube, 23.2\% use LinkedIn, 11.9\% use Flickr, 5.2\% use a blog, and $7.7 \%$ use another social networking product. When comparing public versus private institutions, a greater percentage of the private institutions have implemented every technology, other than blogs. Specifically, Facebook is used by $9.6 \%$ more of the private schools. Moreover, the differences include Twitter by $24.8 \%$ more, YouTube by $62.8 \%$ more, LinkedIn by $23.9 \%$ more, Flickr by $50.4 \%$, and other by $30.8 \%$ more of the private institutions. In contrast, blogs are used by $9 \%$ more of the public institutions. There were no significant differences between public versus private with the exception of YouTube implementation. There was a difference between public and private YouTube usage at the .05 significance level. 


\title{
Issues in Information Systems
}

\author{
Volume XII, No. 2, pp. 1-8, 2011
}

Table 5. Social Network Usage by Institutional Control

\begin{tabular}{||l|r|r|r|r|r|r|r||}
\hline & Facebook & Twitter & YouTube & LinkedIn & Flickr & Blog & Other \\
\hline \hline Public & $36.7 \%$ & $28.1 \%$ & $17.7 \%$ & $18.7 \%$ & $7.9 \%$ & $5.7 \%$ & $5.9 \%$ \\
\hline Private & $40.2 \%$ & $35.1 \%$ & $28.9 \%$ & $23.2 \%$ & $11.9 \%$ & $5.2 \%$ & $7.7 \%$ \\
\hline \% Difference & $9.6 \%$ & $24.8 \%$ & $62.8 \%$ & $23.9 \%$ & $50.4 \%$ & $-9.0 \%$ & $30.8 \%$ \\
\hline Chi-Square Difference & .407 & .082 & $.002 * *$ & .201 & .115 & .798 & \\
\hline
\end{tabular}

** Significant at the .05 level (2-tailed)

Overall, $38 \%$ of the public and $43 \%$ of the private controlled institutions use at least one form of electronic social networking (Table 6). In terms of public institutions, $6 \%$ of schools employ only one technology, $7 \%$ use two technologies, $11 \%$ use three technologies, $7 \%$ use four technologies, $5 \%$ use five technologies, $2 \%$ use six technologies, and $1 \%$ use seven technologies. In terms of private institutions, $4 \%$ of schools employ only one technology, $5 \%$ use two technologies, $11 \%$ use three technologies, $14 \%$ use four technologies, $6 \%$ use five technologies, $3 \%$ use six technologies, and $0 \%$ use seven technologies. When comparing private versus public, $23 \%$ of private institutions implemented four or more products while only $15 \%$ of public institutions did so.

Table 6. Usage of Multiple Social Networking Technologies by Institutional Control

\begin{tabular}{||c|r|r|r||}
\hline Type & \multicolumn{1}{|c|}{ Public } & \multicolumn{1}{|c|}{ Private } & \% Difference \\
\hline \hline Only 1 Technology & $6 \%$ & $4 \%$ & $-41 \%$ \\
\hline Uses 2 Technologies & $7 \%$ & $5 \%$ & $-30 \%$ \\
\hline Uses 3 Technologies & $11 \%$ & $11 \%$ & $5 \%$ \\
\hline Uses 4 Technologies & $7 \%$ & $14 \%$ & $95 \%$ \\
\hline Uses 5 Technologies & $5 \%$ & $6 \%$ & $26 \%$ \\
\hline Uses 6 Technologies & $2 \%$ & $3 \%$ & $79 \%$ \\
\hline Uses 7 Technologies & $1 \%$ & $0 \%$ & $-100 \%$ \\
\hline Overall & $38 \%$ & $43 \%$ & $12 \%$ \\
\hline \hline
\end{tabular}

\section{CONCLUSIONS AND FUTURE RESEARCH}

Results indicate that electronic social networking has been implemented at 39\% of the AACSB accredited schools of business. Facebook is the most common technology, utilized by $37.8 \%$ of institutions. Twitter, the most common microblogging tool, is used by $30.3 \%$ of schools, followed by YouTube (21.3\% of schools), and LinkedIn (20.2\% of schools). The least utilized technologies include Flickr (9.2\% of schools) and blogs (5.5\% of schools). Although $5 \%$ use only one technology, $28 \%$ of firms use three or more technologies. Pearson statistics suggest a high degree (.01 significance level) of correlation between the implementation of each of the technologies.

Findings also demonstrate that implementation varies by institutional control. Facebook, for example, is used at $36.7 \%$ of public institutions versus $40.2 \%$ of private institutions. Twitter is used at $28.1 \%$ of public institutions versus $35.1 \%$ of private institutions. A greater percentage of private institutions utilized each technology with the exception of blogs. The largest discrepancy of usage is with regard to YouTube and Flickr, where 62.8\% and $50.4 \%$, respectively, more private schools utilize the products. 


\section{Issues in Information Systems}

Volume XII, No. 2, pp. 1-8, 2011

In terms of multiple technologies, usage also varies by institution control. Thirty-two percent of public institutions utilized two or more technologies. On the other hand, 39\% of private institutions utilized two or more technologies. Moreover, $15 \%$ of public institutions utilized four or more technologies while nearly one quarter, or $23 \%$, of private institutions did the same.

There are several important implications from the study. One finding is that although a considerable number (39\%) of AACSB accredited institutions apparently find value in electronic social networking, implementation lags far behind the $71 \%$ usage of the largest corporations. Moreover, 44\% of the Fortune 200 employ at least two social networking technologies compared to $34 \%$ of the AACSB institutions.

A second implication is that institutional control may be a determinant with regard to electronic social networking implementation. Private institutions are more likely to utilize a given product and use more products per school than public institutions. It could be hypothesized that given the higher tuition for private institutions and the greater challenge in meeting enrollment and endowment goals, it would be more important for private schools to implement, monitor, and comprehend the benefits of electronic social networking. Social networking and a sense of community are benefits historically associated with private institutions. These new electronic technologies have simply provided a new infrastructure and new conduits for this communication.

A third implication is that most, nearly two-thirds of, AACSB accredited schools of business are either skeptical regarding electronic social networking and/or have not yet found a reason to implement. It is possible that these institutions may believe that these technologies are a bandwidth drain, potential source for security or privacy intrusion, extraordinary expense to support, or simply not beneficial. This furthermore suggests that there may be a tremendous competitive opportunity if an institution moves into social networking. It appears that there are early adopters but the mass market has yet to get involved.

A final implication is that blogs and photo sharing (such as Flickr) are not important to the AACSB institutions. Efforts appear to be concentrated in the most common consumer products such as Facebook, Twitter, YouTube, and LinkedIn.

The limitations of this study are primarily a function of each firm's website and the nature of the research methodology. If a organization utilizes Twitter, for example, but does not have the logo displayed on the web page that is linked from the AACSB web site, then it was not counted. As a result, the social networking participation may be higher than the $39 \%$ found in this study. The second weakness is that due to the nature of the research methodology, the research does not measure communication volume, user volume, or technology effectiveness. Future research needs to examine usage by institutional size and to explore if electronic social networking is a fad or will become a more important facet of communication for institutions of higher learning. The study does, however, begin to clarify that extent of electronic social networking in higher education.

\section{REFERENCES}

1. AACSB (2011). Schools Accredited in Business. AACSB.net, February 1. Available: https://www.aacsb.net/eweb/DynamicPage.aspx?Site=AACSB\&WebKey=ED088FF2-979E-48C6-B10433768F1DE01D

2. AARP (2011). Keeping Up With Kin Online. AARP The Magazine. 54(1A), Jan/Feb, 72. Available: http://pubs.aarp.org/aarptm/20110102_PR?folio=4\#pg72

3. Cardon, P. W., Marshall, B., Norris, D. T., Cho, J., Choi, J., Cui, L., Collier, C., El-Shinnaway, M. M., Goreva, 


\section{Issues in Information Systems}

Volume XII, No. 2, pp. 1-8, 2011

N., Nillson, S., North, M., Raungpaka, V., Ravid, G., Svensson, L., Usluata, A., Valenzuala, J. P., Wang, S. \& Whelan, C. (2009). Online and Offline Social Ties of Social Network Website Users: An Exploratory Study in Eleven Societies. Journal of Computer Information systems, 50(1), 54-64.

4. Case, C. J. \& D. L. King (2010). Cutting Edge Communication: Microblogging At The Fortune 200, Twitter Implementation and Usage. Issues in Information Systems. XI(1), 216-223.

5. Colaner, S. (2009). Social Networking \& Security. www.pctoday.com, 8(5), 60-61.

6. Complete.com (2010). Site Statistics Twitter.com. Complete.com. January 15. Available: http://siteanalytics.compete.com/twitter.com/

7. Conry-Murray, A. (2009). Can Enterprise Social Networking Pay Off? Informationweek.com, 1224, 2329.eWeek Lab Staff (2010). 25 Technologies That Changed The Decade. eweek, 27(3), 18-24.

8. eWeek Lab Staff (2010). 25 Technologies That Changed The Decade. eweek, 27(3), 18-24.

9. FoxNews (2010). Facebook Glitch Sends Wrong Messages, Raises Privacy Questions. FoxNews.com. February 26. Available: http://www.foxnews.com/scitech/2010/02/26/facebook-glitch-sends-wrong-messagesraises-privacy-questions/

10. Gaudin, S. (2011). Facebook Passes Google As Most Visited Site of 2010. Computerworld.com, January 2. Available:

http://www.computerworld.com/s/article/9202938/Facebook_passes_Google_as_most_visited_site_of_2010

11. Gibson, S. (2009). Web 2.0 Tools Gain Enterprise Acceptance. eweek, 26(7), 16-18.

12. Healey, M. (2010). Socially Challenged. Informationweek.com, 1280, 14-22.

13. Laudon, K. C. \& Traver C. G. (2011). E-commerce. 7th edition, Upper Saddle River, NY: Prentice Hall.

14. Liebowitz, J. \& Liebowitz, K. D. (2008). Social Networking in Baltimore: Connection Versus Collection. Journal of Computer Information Systems. 49(1), 2-9.

15. LinkedIn (2011). About Us. LinkedIn.com. January 14. Available: http://press.linkedin.com/about

16. Matheson, K. (2010). A Week Without Facebook? PA. College Tries It Out. The Times Herald, September 19, B-8.

17. McDougall, P. (2009). Banks Build Out Their Online Grapevines. Informationweek.com, 1241, 80.

18. Muller, R. (2010). Top 11 IT Skills for 2011. Globalknowledge.com. December. Available: http://www.globalknowledge.com/training/generic.asp?pageid=2845\&country=United+States

19. Murphy, C. (2010). The Growth Imperative. Informationweek.com, 1278, 25-28.

20. Rapoza, J. (2009). Social Skills. eweek, 26(10), 14-20.

21. Sarrel, M. (2010). Tapping The Positive From Social Networks For Collaboration. eweek, 27(20), 22-26.

22. Sarrel, M. D. (2010). The Biggest Security Threats Right Now. eweek, 27(10), 16-19.

23. Sledgianowski, D. \& Kulviwat S. (2009). Using Social Network Sites: The Effects of Playfulness, Critical Mass and Trust in a Hedonic Context. Journal of Computer Information Systems, 49(4), 74-83.

24. Soat, J. (2010). 7 Questions Key To Social Networking Success. Informationweek.com, 1254, 18-24.

25. Sobel, J. (2010). State of the Blogosphere 2010. technorati.com. November $3 . \quad$ Avaliable: http://technorati.com/blogging/article/state-of-the-blogosphere-2010-introduction/

26. Sturdevant, C. (2011). Socializing In The Enterprise. eweek, 28(1), 22-24.

27. Technorati (2011). Directory of Blogs. January 15. Available: http://technorati.com/blogs/directory/

28. YouTube (2011). YouTube Fact Sheet. YouTube.com. January $14 . \quad$ Available: http://www.youtube.com/t/fact_sheet

29. Wagner, M. (2009). Opportunity Tweets. Informationweek.com, 1232, 24-26.

30. Web 2.0 (2011). Web 2.0. February 1. Available: http://en.wikipedia.org/wiki/Web_2.0 